\title{
Mycorrhizal birch and toxic mine spoil
}

\author{
R. L. Evans and A. Sylvester \\ School of Biological Sciences, Queen Mary College, University of London, \\ London E1 4NS, U.K.
}

Ectomycorrhizal fungi were found growing in association with birch on mine spoils of disused arsenic and copper mines at Gawton and Wheal Josiah in the Tamar Valley, Devon. The birch were found at the fringes of the sites and in scattered pockets but the spoil was largely uncolonised due to its toxicity. Isolates of Paxillus involutus (Batsch: Fr.) Fr., Laccaria laccata (Scop.: Fr.) Berk. \& Br. and Amanita muscaria (L.: Fr.) Hooker from the mine sites and from uncontaminated sites near London were grown in liquid culture in a range of concentrations of arsenic, copper and iron. Three isolates of Paxillus from contaminated sites were more tolerant of arsenic than a London isolate. Differences existed between these tolerant isolates: that from Gawton mine was more tolerant than two strains from Wheal Josiah. With Laccaria, a London isolate was more tolerant to iron than one from Gawton; however, differences in tolerance to copper between these strains were not evident.

A map of Gawton Mine showed concentrations of toxic elements in soils, and locations of fungal fruit bodies. All soils contained high concentrations of copper, arsenic and iron but in some areas, either arsenic or copper was exceptionally high. Fruit bodies of Laccaria laccata were not found on areas of extremely high copper $(0.4 \mathrm{mg} / \mathrm{g}$ soil dry weight). They were present on soil of lower copper content where they were found to accumulate much higher concentrations of this metal than any other species. Laccaria also accumulated very high concentrations of arsenic (mean $1.2 \mathrm{mg} / \mathrm{g}$ fruit body dry wt.). Fruit bodies of $P$. involutus were not limited to particular soils but were widely distributed over the whole site. Neither copper nor arsenic concentrations in these fruit bodies were found to be particularly high in comparison to other species on the site but iron had accumulated to very high levels (mean $5.7 \mathrm{mg} / \mathrm{g}$ ).

In field experiments the mean heights of inoculated and uninoculated birch were calculated eight months after planting out at Wheal Josiah mine. These early results indicated that the young trees inoculated with a Gawton isolate of $P$. involutus were taller than those inoculated with a London isolate, but plants inoculated with either isolate were taller than uninoculated. This experiment is continuing. In a second field experiment the persistence of inoculated mycorrhizal infection on birch roots was examined. Ten months after planting approximately $65 \%$ of root tips were mycorrhizal. Seedlings initially inoculated with L. laccata were found to have only these mycorrhizae present. In contrast, where plants had been inoculated with $P$. involutus, $51 \%$ of the root tips were still mycorrhizal with this fungus but $22 \%$ had now been colonised by Laccaria laccata. 